\title{
Erratum to: Microbial production of poly(hydroxybutyrate) from C1 carbon sources
}

\author{
Kianoush Khosravi-Darani • Zahra-Beigom Mokhtari • \\ Tomohito Amai • Kenji Tanaka
}

Published online: 14 April 2013

(C) Springer-Verlag Berlin Heidelberg 2013

\section{Erratum to: Appl Microbiol Biotechnol (2013) 97:1407-1424}

$$
\text { DOI 10.1007/s00253-012-4649-0 }
$$

For the reference "A viable antibiotic strategy against microbial contamination in biotechnological production of polyhydroxyalkanoates from surplus whey", Biomass Bioenerg 35:748-753, wrong author names have been listed.

The authors are: Koller M, Hesse P, Salerno A, Reiterer A, Braunegg $\mathrm{G}$

The online version of the original article can be found at http://dx.doi.org/ 10.1007/s00253-012-4649-0.

K. Khosravi-Darani $(\bowtie)$

Department of Food Technology Research, National Nutrition and Food Technology Research Institute, Faculty of Nutrition Sciences and Food Technology, Shahid Beheshti University of Medical Sciences, P.O. Box 19395-4741, Tehran, Iran e-mail: k.khosravi@nnftri.ac.ir

\section{Z.-B. Mokhtari}

Department of Chemical Engineering, School of Petroleum and Petrochemical Engineering, Hakim Sabzevari University,

Sabzevar, Iran

T. Amai $\cdot$ K. Tanaka

Department of Biological and Environmental Chemistry, Faculty

of Humanity-Oriented Science and Engineering,

Kinki University, Kayanomori, Iizuka-si,

Fukuoka 820-8555, Japan 